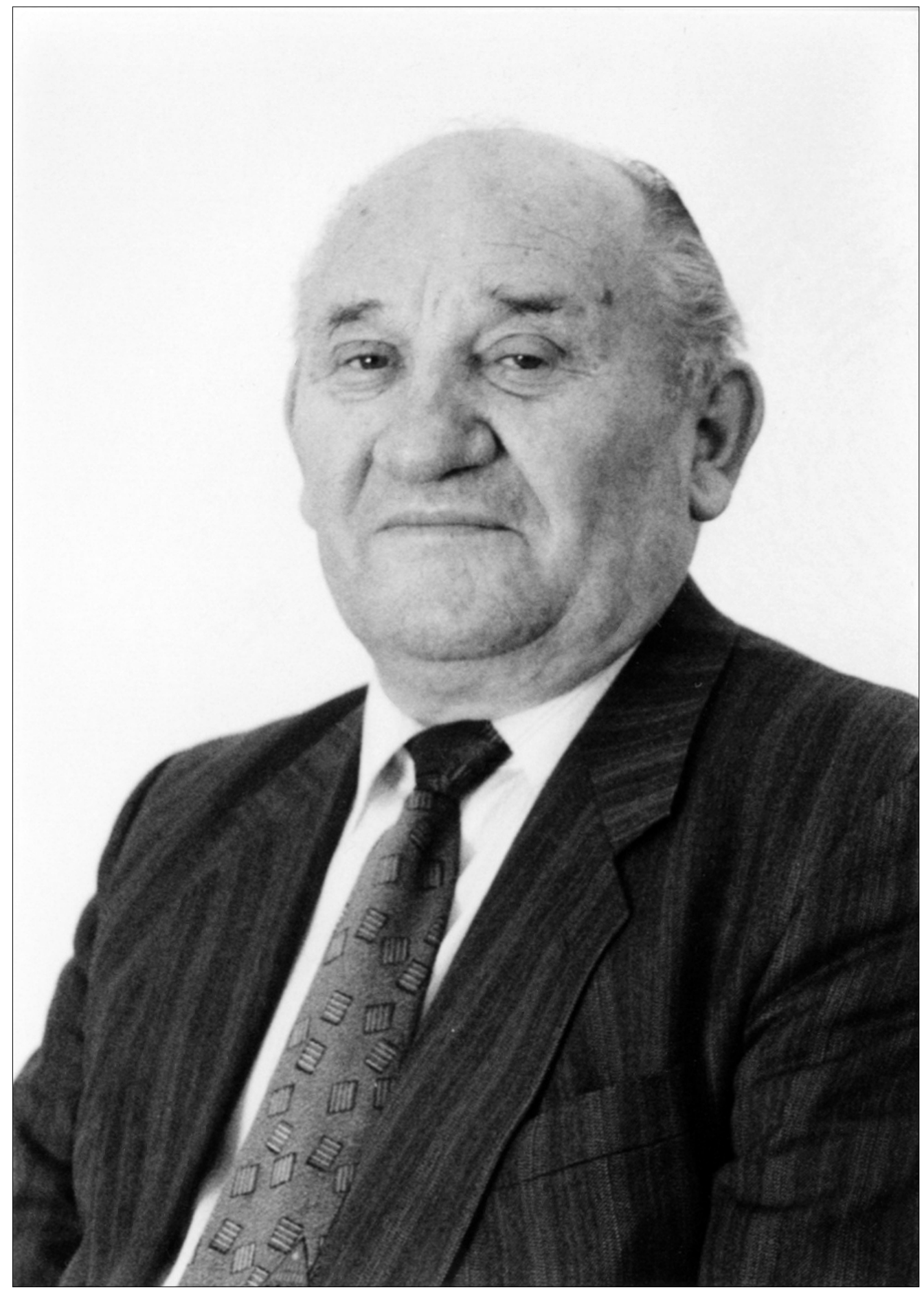

Prof. PhDr. Zdeněk Masařík, DrSc. 



\section{Professor Zdeněk Masařík gestorben}

Eine traurige Nachricht erreichte im Herbst dieses Jahres breite Kreise der Germanisten, weiterer Universitätskollegen sowie in erster Linie die engere Familie: Am 19. Oktober 2016 hat uns im Alter von 88 Jahren Professor PhDr. Zdeněk Masařík, DrSc., verlassen. Was unsere Verabschiedung von ihm in diesem Nachruf doch etwas leichter machen kann, ist die Tatsache, dass wir auf ein zweifellos erfülltes Leben zurückblicken können.

Zdeněk Masařík wurde am 23. März 1928 im südmährischen Dorf Nemotice (Nemotitz), Bezirk Vyškov (Wischau), geboren. Trotz schwieriger Lebensbedingungen in den 1930er und 1940er Jahren konnte er nach dem Abschluss der Grundschule das Gymnasium in Bučovice (Butschowitz) besuchen. Nach dem Abitur 1949 begann er mit dem Studium an seiner Alma Mater, mit der er zukünftig lebenslang verbunden bleiben sollte. Seine Studienfächer an der Brünner Universität waren Deutsch und Russisch (an der Philosophischen Fakultät) und Musikunterricht (an der Pädagogischen Fakultät). Beim Abschluss des Magisterstudiums 1953 standen bereits die Entscheidung für die akademische Laufbahn, ebenso wie die Wahl der Germanistik zum primären Arbeitsgebiet fest. Eine in mancher Hinsicht prägende Rolle mag gewiss auch der Studienaufenthalt in Leipzig gespielt haben, zu dem er nach dem dritten Studienjahr ausgereist war (es handelte sich um den ersten Brünner Studienjahrgang, dem sich in der Nachkriegszeit die Möglichkeit des Studiums in Deutschland eröffnete). Von seinen Lehrern an der Leipziger Universität beeinflussten ihn wohl Theodor Frings, Ludwig Erich Schmitt, Elisabeth Karg-Gasterstädt oder Henrik Becker am meisten. In ihren Arbeitsgebieten lassen sich wahrscheinliche Impulse für manche spätere Forschungsinteressen von Zdeněk Masařík erkennen, sei es im Bereich der historischen Sprachwissenschaft, der Dialektologie, der Kanzleisprache oder in der Untersuchung der Entwicklungstendenzen der Gegenwartssprache. Auch seine Staatsprüfung im Fach Germanistik fand 1953 an der Leipziger Universität statt (das Thema der von H. Becker betreuten Diplomarbeit war die gegenwartssprachliche Lexik).

In der anschließenden Tätigkeit als wissenschaftlicher Aspirant (d.h. Doktorstudent) an der Brünner Universität rückte die Problematik der Kanzleisprache des 14. und 15. Jh. in den Vordergrund. Diesem Themenbereich widmete er eine Reihe von Einzelveröffentlichungen, ferner auch die 1959 an der Prager Karlsuniversität verteidigte Dissertation (zur Erlangung des wissenschaftlichen Grades CSc.) Die Sprache der Brünner deutschen 
Urkunden und später auch die Habilitationsschrift Die mittelalterliche deutsche Kanzleisprache Süd- und Mittelmährens (1965; 1966 publiziert). Seine Promotion-B-Schrift (DrSc.) Die frühneuhochdeutsche Geschäftssprache in Mähren wurde 1984 an der Humboldt-Universität Berlin verteidigt und erschien 1985 in Brünn. Diese Arbeiten zeichnen sich aus durch ihre feste Verankerung in den Quellenrecherchen des handschriftlichen Materials sowie durch eine methodologisch ausgereifte Auswertung. Zu betonen sind auch die interdisziplinären Ansätze, insbesondere die Einbeziehung der Historischen Hilfswissenschaften; aus diesem gemeinsamen Interessensbereich entwickelte sich eine langjährige Zusammenarbeit und lebenslange Freundschaft mit Prof. Miroslav Flodr (1929-2015).

Neben der Kanzleisprachen galt das Interesse von Zdeněk Masařík in altphilologischen Traditionen auch den literarischen Werken im engeren Sinne - zu nennen ist das Nikolsburger Bruchstück des Barlaam und Josaphat Rudolfs von Ems (1974), die gereimte sowie die Prosa-Übersetzung der Dalimil-Chronik (1991, 1993), die nicht veröffentlichten Teiluntersuchungen zur deutschen Übersetzung der Pulkava-Chronik oder dem Werk Nikolaus' von Kosel.

Trotz der intensiven Beschäftigung mit historischen Sprachstufen rückte auch die Problematik der Gegenwartssprache wiederholt in den Blickwinkel von Zdeněk Masařík. Als sein Lieblingsthema kann man die Modalität in ihren vielfältigen Erscheinungsformen nennen. Seine Untersuchungsansätze sind charakteristisch durch die Einbeziehung der sprachkontrastiven Perspektive, insbesondere in dem Vergleich des Deutschen und des Tschechischen. Bei diesen Themen kam der Zusammenarbeit mit Bohemisten eine unersetzliche Rolle zu. Mehrere Veröffentlichungen in diesem Gebiet wurden gemeinsam mit Prof. Miroslav Grepl (* 1929) verfasst.

Nicht zu vernachlässigen ist ferner die langjährige Pflege von persönlichen Kontakten, der wissenschaftlichen Kommunikation und Zusammenarbeit im internationalen Rahmen, die eigentlich sehr früh, bereits in der Studienzeit in Leipzig einsetzte und später während des Lektorats an der Berliner Humboldt-Universität Anfang der 1960er Jahre vertieft werden konnte. Dank dem Humboldt-Stipendium und der zugehörigen Studienreise (z.B. 1968 Deutsches Sprachatlas, Marburg) konnte Z. Masař́́k in den späteren 1960er Jahren auch wissenschaftliche Kontakte mit Forschern aus der damaligen BRD anknüpfen; in manchen Fällen entwickelten sich aus den professionellen Beziehungen auch langjährige persönliche Freundschaften (z.B. Günter Bellmann, Hans Peter Althaus, später Norbert Richard Wolf, Albrecht Greule u.v.a.m.). In den 1970er-1980er Jahren war die Betätigung im internationalen Kontext wieder erschwert und eingeschränkt. Zu erwähnen ist jedenfalls die Arbeit in der Germanistenkommission DDR - ČSSR. Im Jahre 1983 wurde Z. Masařík als Würdigung seiner Verdienste um die Erforschung der deutschen Sprache und die Koordination der sprachhistorischen Forschung der Jacobund-Wilhelm-Grimm-Preis verliehen.

Eine besondere Erwähnung verdient die Gründung und die anschließende redaktionelle Leitung des germanistischen Fachperiodikums Brünner Beiträge zur Germanistik und Nordistik (1977), das sich von einem Publikationsmedium für Lehrstuhlmitglieder bald zu einer offenen germanistischen Fachzeitschrift entwickelte, deren Profil von dem Gründer maßgeblich mitbestimmt wurde. Dasselbe kann man in gleicher Weise von 
seinen weiteren Betätigungsgebieten und Vorhaben sagen - der Initiierung und langjährigen Leitung des Germanistenverbandes der Tschechischen Republik sowie den von ihm abgeschlossenen Institutspartnerschaften u.a.

Die akademische Laufbahn Zdeněk Masaříks an der Brünner Philosophischen Fakultät umfasste die Anstellung als wissenschaftlicher Aspirant (1953-1956), anschließend (1956-1966) als Fachassistent; 1960 erhielt er den Titel Kandidat der philologischen Wissenschaften (CSc.); 1960-1962 wirkte er als Lektor für die tschechische Sprache an der Humboldt-Universität in Berlin. In den weiteren Jahren erfolgte seine Ernennung zum Dozenten (1966), 1984 erwarb er nach an der Humboldt-Universität den Titel Doktor der philosophischen Wissenschaften (Dr. sc. phil.), der dann in der Tschechoslowakei anerkannt wurde (DrSc.); schließlich wurde er zum Professor für germanische Philologie (1986) berufen. Nach der Emeritierung von Prof. Leopold Zatočil 1971 war Z. Masařík lange Jahre (1971-1991) als Leiter des Lehrstuhls für Germanistik und Nordistik tätig; vorübergehend leitete er sogar gleichzeitig auch den Lehrstuhl für Anglistik und Amerikanistik (1984-1989), für dessen Aufrechterhaltung als autonomes Institut er sich dadurch verdient gemacht hat. In den Jahren 1987-1989 war er auch Prodekan der Philosophischen Fakultät. Auch nach seiner Emeritierung 1993 beteiligte sich Professor Masařík weiterhin bis 2012 am Unterricht und auch danach blieb er im aktiven Kontakt mit unserem Institut.

Neben der kaum zu überschätzenden Bedeutung für die Brünner Germanistik bzw. die gesamte Philosophische Fakultät hat sich Zdeněk Masařík auch um Germanistische Institute und Studiengänge an anderen Universitäten verdient gemacht. Bereits Anfang der 1990er Jahre beteiligte er sich persönlich an der Gründung der germanistischen Studien an der Schlesischen Universität in Opava (Troppau) und seit der Mitte der 90er Jahre war er auch an der Ostrauer Universität tätig.

Generationen von Studenten (nicht nur die Germanisten, sondern auch z.B. die Studierenden der Historischen Hilfswissenschaften und der Archivkunde) schätzten seine Fachkompetenz, prägnante Ausdrucksweise und die Anschaulichkeit seiner Ausführungen, die auch seine zahlreichen Lehrbücher und Lehrmaterialien charakterisieren. Auch bei den von ihm betreuten Diplomanden und Doktoranden bzw. den Institutskollegen und Freunden war Professor Masař́k sehr beliebt und respektiert - nicht nur wegen seiner umfassenden Kenntnisse, Erfahrungen und dem pädagogischen Geschick, sondern auch wegen seiner Offenheit, seinem Sinn für Gerechtigkeit und seiner Hilfsbereitschaft.

$\mathrm{Zu}$ bestimmten Anlässen kam auch die musikalische Seite seines Naturells zum Vorschein. Manche werden sich an seine Akkordeon-Darbietungen erinnern; in seiner Heimatgemeinde Nemotice, in die er sein Leben lang immer wieder zurückkehrte, war er lange als Organist in der dortigen Hl.-Wenzel-Kirche tätig. Hier fand sein tiefer Glaube Ausdruck und gewissermaßen auch seine frühe musikdidaktische Schulung, denn es gelang ihm seinen Nachfolger vorzubereiten. Seinem geliebten Geburtsort, wo er jahrelang an Wochenenden und in den Ferien manuell arbeitete, widmete sich Z. Masařík auch in einer historisch-landeskundlichen Arbeit (2007), in der er seine reichen Erfahrungen mit Quellenrecherchen und -analysen verwertete.

Alle behalten auch seinen ausgeprägten Sinn für Humor in Erinnerung - sei es in seinen beliebten aktuell glossierenden Sprüchen oder seinen lebhaften Erzählungen, in 
denen er mit bewundernswertem Detailreichtum Lebensgeschichten, die Hintergründe der Forschungsarbeit sowie das allgemeine Zeitgeschehen einem Zuhörerkreis näher zu bringen wusste. Unvergesslich geworden sind unter anderem einige schlagfertige Sprüche, in denen sich Sprachwitz und eigene Forschungsinteressen vereinten (etwa die Feinheiten im Bereich der Modalität): „... Ob Sie können, lieber Kollege, weiß ich nicht - aber Sie dürfen. ... “Sprichwörtlich ist ebenfalls seine sorgsame Beachtung der „außersprachlichen Fakten" geworden - was nicht nur einen erprobten methodischen Grundsatz bei der eigentlichen Forschungsarbeit darstellte, sondern im weiteren Sinne auch seine Offenheit und reges Interesse für Freuden und Schmerzen seiner Mitmenschen kennzeichnete.

Lieber Herr Professor, wir sind dankbar, dass wir Ihnen begegnen und Sie zum Lehrer, Kollegen und Freund haben konnten (/durften)! 


\section{Bibliographie von Zdeněk Masařík}

Die Publikationen sind in aufsteigender chronologischer Reihenfolge angeführt; innerhalb desselben Erscheinungsjahres dann jeweils alphabetisch nach Titel sortiert. Durch die Kursivschrift werden stets die Titel der Veröffentlichungen von Z. Masařík abgedruckt (auch in Zeitschriften und Sammelbänden). Die Namen der Verfasser werden nur bei mehreren Autoren ausdrücklich angeführt. Die Erscheinungsjahre wurden zur besseren Übersichtlichkeit durch Fettdruck hervorgehoben. Editorische Ergänzungen, Erläuterungen, Übersetzungen der Titel u.a. stehen in eckigen Klammern.

\section{Abkürzungen}

BBGN - Brünner Beiträge zur Germanistik und Nordistik - erscheinen seit 1977; zwischen 1979 und 1994 in der Schriftenreihe Sbornik praci filozofické fakulty brněnské univerzity (SPFFBU). Řada germanisticko-anglistická $(K)$ - Studia minora facultatis philosophicae universitatis Brunensis. Series Germanica et Anglica (K). Zwischen 1996 und 2008 in der Reihe Sbornik praci filozofické fakulty brněnské univerzity. Řada germanistická $(R)$ - Studia minora facultatis philosophicae universitatis Brunensis. Series Germanica (R). Brno: Filozofická fakulta MU.

SPFFBU - Sbornik praci filozofické fakulty brněnské univerzity - Studia minora Facultatis philosophicae Universitatis Brunensis. Brno: Filosofická fakulta.

Zur Situation des deutschen Wortschatzes nach 1945 (Dipl.; masch.). Leipzig 1953. (Betreuer Prof. Henrik Becker).

Walter Jung: Kleine Grammatik der deutschen Sprache. Lipsko (Bibliografický institut) 1953, stran 284. In: SPFFBU 3, 1954, A 2, S. 116-117.

Duden. Bildwörterbuch (Deutsch und Russisch). Leipzig 1953 (XX + 700 S.). In: Časopis pro moderní filologii 38/5, 1956, S. 308.

Luther a vznik spisovného jazyka německého [Luther und die Entstehung der deutschen Schriftsprache]. In: SPFFBU 5, 1956, A 4, S. 141-142.

Sovětský př́spěvek k Engelsovu „Franckému dialektu“ [Ein sowjetischer Beitrag zum Engels” „Fränkischen Dialekt"]. In: Časopis pro moderní filologii 38/3, 1956, S. 169-170.

Jazykové poznámky k Rösslerovu vydání brněnských městských práv [Sprachliche Anmerkungen zur Rösslers Ausgabe der Brünner Stadtrechte]. In: Časopis Matice Moravské 75/1-2, 1957, S. 147-152.

K jazyku tzv. Otakarovského městského práva pražského [Zur Sprache des sog. Ottokarschen Prager Stadtrechtes]. In: Časopis Matice Moravské 76/3-4, 1957, S. 384-389.

M. M. Guchman, Ot jazyka nemeckoj narodnosti k nemeckomu nacional'nomu jazyku. Čast' I., Razvitije jazyka nemeckoj narodnosti. Akademija nauk SSSR, Moskva 1955, stran 161. In: SPFFBU 6, 1957, A 5, S. 135-136.

O. Behaghel, Die deutsche Sprache. Halle (Saale) 1953, VII + 308 S. In: Časopis pro moderní filologii 39/1, 1957, S. 59.

O. I. Moskalskaja, Grammatika německogo jazyka. Moskva 1956. 387 S. In: Cizí jazyky ve škole 2/2, 1958, S. 88-90.

Průvodce Goethovým domem [Übersetzung des deutschen Originals: Goethehaus in Weimar]. Weimar 1958.

Die Sprache der Brünner deutschen Urkunden (Diss./CSc.; masch.). verteidigt 1959, Karlsuniversität, Prag. 
Einige Bemerkungen zur Erforschung der deutschen Urkundensprache. In: SPFFBU 8, 1959, A 7, S. 65-73.

N. I. Filičeva, Istorija německogo jazyka. Moskva 1959. 280 S. In: SPFFBU 9, 1960, A 8, S. 157-159. Zum Lautstand der Brünner deutschen Urkunden. In: SPFFBU 10, 1961, A 9, S. 113-123.

Německo-česká konverzace [Deutsch-tschechische Konversation (bestimmt für die Zollverwaltung der DDR)]. Berlin 1962. (48 S.)

Erwin Arndt, Luthers deutsches Sprachschaffen. Berlin 1962. 215 S. In: SPFFBU 14, 1965, A 13, S. 240-242.

Karlheinz Daniels, Substantivierungstendenzen in der deutschen Gegenwartssprache. Päd. Verlag Schwann, Düsseldorf 1963, 249 S. In: SPFFBU 14, 1965, A 13, S. 242-244.

Profesor Leopold Zatočil šedesátiletý [Prof. Leopold Zatočil sechzigjährig]. In: SPFFBU 14, 1965, A 13, S. 5-6. (+ Bibliographie S. 6-10). [Autorenangabe: „Pracovní kolektiv katedry germanistiky“] Zur mittelalterlichen deutschen Kanzleisprache in Znaim. In: SPFFBU 14, 1965, A 13, S. 115-120.

Chronicon Henrici de Mügeln Germanice conscriptum. In: BARTOŇKOVÁ, Dagmar (et al.) (hrsg.): Magnae Moraviae fontes historici I. (Annales et chronicae), Praha: Státní pedagogické nakladatelství 1966 (Opera Universitatis Purkynianae Brunensis, Facultas philosophica, Nr. 104), S. 293-297. [Teiledition]

Die mittelalterliche deutsche Kanzleisprache Süd- und Mittelmährens. Brno 1966. (146 S.)

Historický vývoj němčiny. Praha: Státní pedagogické nakladatelství 1966. (100 S.) [Lehrbuch]

Fritz Tschirch, Geschichte der deutschen Sprache. Erster Teil. Berlin 1966. 192 S. In: Zeitschrift für Mundartenforschung 34/2, 1967, S. 161-163.

Otfrids von Weissenburg Evangelienbuch. In: BARTOŇKOVÁ, Dagmar (et al.) (hrsg.): Magnae Moraviae fontes historici II (Textus biographici, hagiographici, liturgici). Brno: Universita J. E. Purkyně 1967 (Opera Universitatis Purkynianae Brunensis, Facultas philosophica, Nr. 118), S. 321. [Teiledition]

Zur spätmittelalterlichen Wortgeographie. (Wochentagnamen der deutschen Kanzleisprache des 14.-16. Jh. in Mähren.). In: Zeitschrift für Mundartenforschung 34/3-4, 1967, S. 281-289.

Gerhard Kettmann, Die kursächsische Kanzleisprache zw. 1486 u. 1546. Akademie-Verlag Berlin 1967. 309 S. In: Zeitschrift für Mundartenforschung 35/2, 1968, S. 169-172.

Johannes Hansel, Bücherkunde für Germanisten. Berlin 1967. 163 S. In: Muttersprache 78/6, 1968, S. 182-183.

L. E. Schmidt, Untersuchungen zu Entstehung und Struktur der „neuhochdeutschen Schriftsprache“. I. Bd., Sprachgeschichte des Thüringisch-Obersächsischen im Spätmittelalter. Die Geschäftssprache von 1300 bis 1500. Böhlau Verlag Köln/Graz 1966, S. 686 + Kartenteil. In: SPFFBU 17, 1968, A 16, S. 159-161.

Z činnosti marburského dialektologického pracoviště [Über die Tätigkeit der Marburger Forschungsstelle zur Dialektologie]. In: Časopis pro moderní filologii 50/1, 1968, S. 34-38.

Zwei Jubiläen im „Forschungsinstitut für deutsche Sprache“ in Marburg. In: Philologica Pragensia 1968, 2, S. 113-114.

Fritz Tschirch: Geschichte der deutschen Sprache II. Berlin: Erich Schmidt 1966. In: Zeitschrift für Dialektologie und Linguistik 34/2 [früher Zeitschrift für Mundartforschung], 1969, S. 243-245.

Historický vývoj němčiny. (2. Aufl.) Praha: Státní pedagogické nakladatelství 1969. (110 S.) [Lehrbuch]

Werner Besch: Sprachlandschaften und Sprachausgleich im 15. Jh. Studien zur Erforschung der spätmittelalterlichen Schreibdialekte und zur Entstehung der neuhochdeutschen Schriftsprache. (= Bibliotheca germanica 11). Francke Verl. München 1967, S. 426. In: SPFFBU 18, 1969, A 17, S. 201-202.

Zehnter Internationaler Kongress für Namenforschung Wien, 8.-13. September 1969. In: Zeitschrift für Dialektologie und Linguistik 36/3, 1969, S. 334-336 
Zur Sprache des ältesten Stadtbuches in Mähr. Schönberg. In: SPFFBU 18, 1969, A 17, S. 123-130.

K pětašedesátinám doc. dr. Krejčího [Zum fünfundsechzigsten Geburtstag von Doz. Dr. Krejčí]. In: Universitas 3/1, 1970, S. 80-81.

K pětašedesátým narozeninám prof. dr. Leop. Zatočila, DrSc. [Zum fünfundsechzigsten Geburtstag von Prof. Dr. Leopold Zatočil, DrSc.]. In: Časopis pro moderní filologii 52/4, 1970, S. 213-215.

Ilpo Piirainen, Graphematische Untersuchungen zum Frühneuhochdeutschen. Berlin. Walter de Gruyter, 1968. (Studia Linguistica Germanica 1.), 270 S. In: SPFFBU 20, 1971, A 19, S. 256-257.

Středověká bavorská enkláva u Olomouce. In: Slezský sborník 69/3, 1971, S. 290-296.

MASAŘÍK, Zdeněk - GREPL, Miroslav: Zum Ausdruck der voluntativen Modalität im Tschechischen und Deutschen. In: Bulletin institutu prekladatelstva a tlmočníctva I, Bratislava: Univerzita 17. Novembra 1971, S. 17-34.

Horacek, Blanka: Kleine historische Lautlehre des Deutschen. Wien/Stuttgart, 1966. 110 S. In: Muttersprache 82/2, 1972, S. 124.

O. I. Moskalskaja, Grammatik der deutschen Gegenwartssprache Verlag „Hochschule“, Moskau 1971. 383 S. In: Cizí jazyky ve škole 16/8, 1972/73, S. 381-383.

Die voluntative Modalität im Tschechischen und Deutschen konfrontativ betrachtet. In: Otázky slovanské syntaxe III, Sborník symposia „Modální výstavba výpovědi v slovanských jazycích“, Brno 27.-30. září 1971 [redigoval kolektiv katedry českého jazyka a katedry ruského jazyka na filosofické fakultě UJEP]. Brno: Universita J. E. Purkyně 1973, S. 221-225.

Nikolsburger Bruchstück des Barlaam und Josaphat von Rudolf von Ems. In: Beiträge zur Geschichte der deutschen Sprache und Literatur 95, Halle (Saale), 1974, S. 388-402.

MASAŘÍK, Zdeněk - GREPL, Miroslav: Zum Ausdruck der Gewißheitsmodalität im Tschechischen und Deutschen. In: Acta universitatis XVII. Novembris Pragensis. Bulletin odboru prekladatelstva a tlmočníctva. Bratislava: Univerzita 17. Novembra, Fakulta spoločenských vied 1974, S. 49-80.

MASAŘÍK, Zdeněk - GREPL, Miroslav: Zur Kategorie der Modalität im Deutschen und Tschechischen aus konfrontativer Sicht. In: Deutsch als Fremdsprache 11/6, 1974, S. 370-378.

Das Stadtrechtsbuch von Sillein. Einleitung. Edition und Glossar von I[l]po Ta[pa]ni Piirainen. Walter de Gruyter, Berlin/New York 1972. In: SPPFFBU 1972, A 20, S. 263-264.

MASAŘÍK, Zdeněk - UHROVÁ, Eva: Alt- und mittelhochdeutsche Texte. Mit Hinweisen zur Interpretation. Brno: Univerzita Jana Evangelisty Purkyně 1974. (125 S.) [Lehrbuch]

Prof. dr. Zatočil, DrSc., sedmdesátiletý [Prof. Dr. [Leopold] Zatočil, DrSc., siebzigjährig]. In: SPFFBU 23/24, 1974/1975, A 22/23, S. 5-6 (+ Bibliographie von L. Zatočil S. 6-7).

Sedmdesátiny Leopolda Zatočila [Der siebzigste Geburtstag von Leopold Zatočil]. In: Universitas 8/5, 1975, S. 94-95.

Zur mittelalterlichen deutschen Kanzleisprache Nordwestmährens. In: SPFFBU 23/24, 1974/1975, A 22/23, S. 185-197.

Katedra germanistiky a nordistiky [Lehrstuhl für Germanistik und Nordistik]. In: Ročenka Univerzity J. E. Purkyně, Brno 1976, S. 783-786.

Ein Beitrag zur deutschen Kanzleisprache in Olmütz im 15. und 16. Jh. In: BBGN 1, 1977, S. 23-44.

Vývoj mluvnického systému němčiny [Entwicklung des grammatischen Systems des Deutschen]. Brno: Univerzita Jana Evangelisty Purkyně 1977. (176 S.) [Lehrbuch]

MASAŘÍK, Zdeněk - UHROVÁ, Eva: Alt-und mittelhochdeutsche Texte. Mit Hinweisen zur Interpretation. Brno: Univerzita Jana Evangelisty Purkyně 1978 [Nachdruck der 1. Aufl.] (125 S.) [Lehrbuch]

Claus Jürgen Hutterer: Die germanischen Sprachen. Ihre Geschichte in Grundzügen. Akadémiai Kiadó, Budapest 1975. 543 S. In: SPFFBU 26/27, 1978, A 25/26, S. 188-190.

$K$ vyjadřováni jistotni modality v čěstině a němčině [Zum Ausdruck der Gewissheitsmodalität im Tschechischen und im Deutschen]. In: Slovo a slovesnost 40, 1979, S. 190-193. 
Poznámky k starohornoněmecké monoftongizaci a diftongizaci [Bemerkungen zur althochdeuschen Monophthongierung und Diphthongierung]. In: SPFFBU 28, 1979, A 27, S. 107-112.

Poznámky $k$ středověké němč̀ně na jihovýchodni Moravě [Bemerkungen zum mittelalterlichen Deutsch in Südostmähren]. In: Časopis Matice Moravské 98/3-4, 1979, S. 326-334.

Spolupráce brněnských germanistů s NDR [Die Zusammenarbeit der Brünner Germanisten mit der DDR]. In: Universitas 12/4, 1979, S. 86-89.

MASǍ̌ÍK, Zdeněk - GREPL, Miroslav: Zur Kategorie der Modalität im Deutschen und Tschechischen aus konfrontativer Sicht. In: JÄGER, Gert (hrsg.): Lesebuch zum tschechisch-deutschen Sprachvergleich (Lehrbücher und Arbeitsmaterialien zum Studium der tschechischen Sprache, Nr. 11). Leipzig: Karl-Marx-Universität 1979, S. 109-129.

Nástin historického vývoje nĕmčiny do doby raně nové [Aufriss der historischen Entwicklung des Deutschen bis zur Frühen Neuzeit]. In: KUBÍK, Miloslav - SCHMIDT, Wilhelm (et al.) (hrsg.): Jazykověda a příprava učitelů jazyků I. Praha: Univerzita Karlova 1980, S. 89-110.

Prof. Zatočil pětasemdesátiletý [Prof. Zatočil siebzigjährig]. In: Universitas 13/5, 1980, S. 94.

Stefan Sonderegger, Grundzüge deutscher Sprachgeschichte Bd. 1. W. de Gruyter, Berlin 1979. XV + 353 S. In: BBGN 2, 1980, S. 176-177.

Zu einigen Fragen der Modalität im Deutschen und Tschechischen. In: RUPP, Heinz - ROLOFF, HansGert (hrsg.): Akten des VI. Internationalen Germanistenkongresses, Basel 1980 (Jahrbuch für internationale Germanistik 8). Frankfurt am Main - Bern: Peter Lang Verlag 1980, S. 163-168.

Zum Ausdruck der voluntativen Modalität im Deutschen in diachronischer Sicht - mit einigen Aspekten der Konfrontation mit dem Tschechischen. In: BBGN 2, 1980, S. 29-45.

Zur Stratifikation der bairisch-mitteldeutschen Bestandteile des Frühneuhochdeutschen in Mähren. In: Walther von der Vogelweide - Kolloquium. Referate und Diskussionsbeiträge des Kolloquiums zu aktuellen Fragen der Erforschung der mittelalterlichen deutschen Sprache und Literatur in der Tschechoslowakei. České Budějovice: Pedagogická fakulta 1980, S. 21-35.

Poznámky k tzv. větným modifikátorům v němčině a čěstině [Bemerkungen zu sog. Satzmodifikatoren im Deutschen und Tschechischen]. In: Cizí jazyky ve škole 25/3, 1981/1982, S. 110-115.

Vorüberlegungen zu den sog. Satzadverbien im Deutschen und Tschechischen. In: BBGN 3, 1982, S. 21-35. Vývoj mluvnického systému němčiny. (Nachdruck der 1. Aufl.) Brno: Univerzita Jana Evangelisty Purkyně 1982. [Lehrbuch]

Die frühneuhochdeutsche Geschäftssprache in Mähren. Brno: Universita J. E. Purkyně 1985. (246 S. + 6 S. Beilagen)

Zu Bestand und Entwicklungstendenzen der hypotaktischen Konjunktionen des Frühneuhochdeutschen in Mähren. In: BBGN 4, 1984, S. 15-55.

Zur Bedeutung des Bairischen für die frühneuhochdeutsche Schreibsprache in Mähren. In: WIESINGER, Peter (hrsg.): Beiträge zur Bairischen und ostfränkischen Dialektologie. Göppingen 1984 (Göppinger Arbeiten zur Germanistik, Bd. 409), S. 181-190.

Zur Frage der Partikeln bei M. Luther. In: Linguistische Studien, Reihe A, 119/3, 1984, Berlin: Akademie der Wissenschaften der DDR, Zentralinstitut für Sprachwissenschaft, S. 2-16.

Zu einigen Triebkräften der Ausgleichsprozesse des Frühneuhochdeutschen in Mähren. In: brücken. Germanistisches Jahrbuch DDR-ČSSR 1984/1985, S. 91-104.

Interkulturelle Verständigung und Fremdsprachenunterricht. In: Deutsch als Fremdsprache 23/1, 1986, S. 11-12.

Světový kongres germanistů [Weltkongress der Germanisten]. In: Universitas 19/6, 1986, S. 79.

Theoretische und methodologische Probleme der frühneuhochdeutschen Kanzleisprache diskutiert auf der Basis vom Material aus Mähren. In: Beiträge zur Erforschung der deutschen Sprache 6, 1986, S. 136-143. 
Zu einigen Partikeln im Deutschen Wörterbuch der Brüder Grimm. In: Sprache, Mensch und Gesellschaft: Werk und Wirkungen von Wilhelm von Humboldt und Jacob und Wilhelm Grimm in Vergangenheit und Gegenwart. Humboldt-Grimm-Konferenz, Berlin, 22.-25. Okt. 1985. Protokollband III, hrsg. von Arwed SPREU und Wilhelm BONDZIO. Berlin: Humboldt-Universität, Sektion Germanistik 1986, S. 57-63.

Zur Sprachschichtung im Deutschen und Tschechischen aus terminologischer Sicht. In: BBGN 5, 1986, S. 79-87.

Die Entwicklung der finalen Konjunktionen des Frühneuhochdeutschen in Mähren. In: brücken, Germanistisches Jahrbuch DDR-ČSSR 1986/1987, S. 173-180.

Karl und Galie. Karlmeinet, Teil I., hrsg. Dagmar Helm (= Deutsche Texte des Mittelalters. Bd. LXXIV.), Akademie-Verlag, Berlin 1986, VIII + 543 S. In: BBGN 6, 1988, S. 155-156.

Wilhelm Schmidt und Kollektiv, Geschichte der deutschen Sprache. 5. überarbeitete und erweiterte Auflage. Volk und Wissen, Berlin 1984, 412 S. In: BBGN 6, 1988, S. 148-149.

Die Mundartmischung im Frühneuhochdeutschen Mittelmährens. In: PUTSCHKE, Wolfgang - VEITH, Werner - WIESINGER, Peter (hrsg.): Dialektgeographie und Dialektologie. Günter Bellmann zum 60. Geburtstag von seinen Schülern und Freunden (Deutsche Dialektgeographie 90). Marburg: Elwert 1989, S. 269-278.

Historische Entwicklung des Deutschen. Praha: Státní pedagogické nakladatelství 1989. (165 S.) [Lehrbuch]

Konfrontačni a historicko-srovnávaci studium cizich jazyků a češtiny [Kontrastives und historisch-vergleichendes Studium der Fremdsprachen und des Tschechischen]. In: Universitas 22/3, 1989, S. 22-24

(„Zu einigen Fragen des Germanistikstudiums in der Tschechoslowakei. Institut für deutsche Sprache. Kongreßmaterialien, 10 S., 1989“ "[Angabe nach MALÁ (1998, S. 13); die angeführte vorläufige Bibliographie konnte nicht vervollständigt oder verifiziert werden])

Zur Wiedergabe der konditionalen Relation in den frühneuhochdeutschen Dialekten Mährens. In: KOLLER, Erwin - FRISCH, Regina (hrsg.): Bayerisch-österreichische Dialektforschung: Würzburger Arbeitstagung 1986. Würzburg: Königshausen \& Neumann 1989. (=Würzburger Beiträge zur deutschen Philologie 1), S. 187-193.

Triebkräfte der Sprachmischung in den Sprachinselmundarten. In: IWASAKI, Eijiro (hrsg.): Begegnung mit dem „Fremden“. Grenzen - Traditionen - Vergleiche. (Akten des VIII. Internationalen Germanisten-Kongresses, Bd. 3: Sprachgeschichte, Sprachkontakte im germanischen Sprachraum, hrsg. von Shichiji YOSHINORI). München: iudicium 1990, S. 89-96.

Zur Sprache der mittelhochdeutschen Dalimilchronik. In: BBGN 7, 1991, S. 51-64.

Gerhard Helbig / Agnes Helbig, Lexikon deutscher Modalwörter. Verlag Enzyklopädie, Leipzig 1990, 300 S. In. BBGN 8, 1992, S. 112-113.

Za profesorem Zatočilem [Nachruf für Prof. Zatočil]. In: Časopis pro moderní filologii 74/1, 1992, S.61-63.

Zur Partikellexikographie aus konfrontativer Sicht. In: BBGN 8, 1992, S. 35-42.

Die Ausdrucksmittel der Modalität im Deutschen und Tschechischen aus konfrontativer Sicht. In: Roggausch, Werner (hrsg.): Dokumentation der Tagungsbeiträge - Germanistentreffen Bundesrepublik Deutschland - ČSFR 6.-10. 10. 1992, Passau. Bonn: DAAD [1993], S. 205-217.

Antonín Beer a široce pojatá germanistika v Brně [Antonín Beer und die breit aufgefasste Germanistik in Brünn]. In: Brněnská věda a umění meziválečného období (1918-1939) v evropském kontextu. Sborník příspěvků z konference Masarykovy univerzity konané v rámci oslav 750. výročí udělení městských práv Brnu ve dnech 22.-25. září 1993. Brno: Masarykova univerzita 1993, S. 76-79.

Historická němčina pro archivářre [Historisches Deutsch für Archivare]. Brno: Masarykova univerzita 1993. (133 S.) [Lehrbuch] 
Sprachliches zur prosaischen Übersetzung der sog. Dalimilchronik. In: MATTHEIER, Klaus J. - WEGERA, Klaus-Peter - HOFFMANN, Walter - MACHA, Jürgen (hrsg.): Vielfalt des Deutschen: Festschrift für Werner Besch. Frankfurt/Main: Peter Lang 1993, S. 241-251.

Bemerkungen zum analytischen Futur im Deutschen. In: BBGN 9, 1994, S. 61-67.

Historische Entwicklung des Deutschen. (2. Aufl.). Brno: Vydavatelství Masarykovy university 1994. (165 S.) [Lehrbuch]

Alena Šimečková: Untersuchungen zum „trennbaren“ Verb im Deutschen I. (Acta Universitatis Carolinae. Philologica. Monographia CXIX). Praha 1993, 127 S. In: BBGN 10, 1996, S. 112-113.

Historická němčina pro archiváře [Historisches Deutsch für Archivare]. (Nachdruck der 1. Aufl.) Brno: Masarykova universita 1997. (133 S.) [Lehrbuch]

Bemerkungen zur mittelbairischen Enklave bei Olmütz. In: ERNST, Peter - PATOCKA, Franz (hrsg.): Deutsche Sprache in Raum und Zeit. Festschrift für Peter Wiesinger zum 60. Geburtstag. Wien: Edition Praesens 1998, S. 87-95.

Germanistik in Lehre und Forschung in der Tschechischen Republik. In: GRUCZA, Franciszek - KOLAGO, Lech - NAMOWICZ, Tadeusz - WIKTOROWICZ, Józef (hrsg.): Deutsch und Auslandsgermanistik in Mitteleuropa. Geschichte-Stand-Ausblicke, Warszawa: Wydawnictwo Graf-Punkt 1998, S. 101-110.

MASAŘÍK, Zdeněk - KRATOCHVÍLOVÁ, Iva: Entwicklungstendenzen in der deutschen Sprache des 20. Jh. Opava: Ústav cizích jazyků Filozoficko-přírodovědecké fakulty Slezské univerzity 1998. (142 S.) [Lehrbuch]

$\mathrm{Zu}$ Entstehung und Werdegang der deutschen Inselmundarten in Mähren. In: HUTTERER, Claus Jürgen - PAURITSCH, Gertrude (hrsg.): Beiträge zur Dialektologie des ostoberdeutschen Raumes: Referate der 6. Arbeitstagung für bayerisch-österreichische Dialektologie, 20.-24. 9. 1995 in Graz (Göppinger Beiträge zur Germanistik Nr. 638), Göppingen: Kümmerle Verlag 1998, S. 43-54.

Zum tschechisch-deutschen/österreichischen Sprachkontakt (dargestellt am Beispiel Südmähren-Niederösterreich). In: BAUER, Werner - SCHEURINGER, Hermann (hrsg.): Beharrsamkeit und Wandel. Festschrift für Herbert Tatzreiter zum 60. Geburtstag. Wien: Edition Praesens 1998, S. 133-141.

Vaňková, L.: Die frühneuhochdeutsche Kanzleisprache des Kuhländchens: Eine Ostrauer Monographie. In: Zbliżenia Polska - Niemcy. Pismo Uniwersytetu Wrocławskiego 25, 2000/1, Wrocław: Uniwersytet Wrocławski, S. 125-126.

Vzpominka na prof. Dr. Antonina Beera [Eine Erinnerung an Prof. Dr. Antonin Beer]. Universitas 33/1, 2000, S. 38-39.

Die Erforschung der frühneuhochdeutschen Kanzleisprache in Mähren. Ergebnisse und Ausblick. In: GREULE, Albrecht (hrsg.): Deutsche Kanzleisprachen im europäischen Kontext: Beiträge zu einem internationalen Symposium an der Universität Regensburg, 5. bis 7. Oktober 1999. (= Beiträge zur Kanzleisprachenforschung, herausgegeben von Jörg MEIER und Arne ZIEGLER, Bd. 1). Wien: Edition Praesens 2001, S. 75-84.

Beer, Antonín und Zatočil, Leopold. In: KÖNIG, Christoph (hrsg.): Internationales Germanistenlexikon (1800-1950) I-III. Berlin [u.a.]: de Gruyter 2003, S. 116-117, 2088-2089. [Lexikoneinträge]

Brünner germanistisches Jubiläum. In: BBGN 19, 2005, S. 17-19. [zum 60. Geburtstag von Doz. Jaromír Zeman] (+ Bibliographie von J. Zeman: S. 19-21)

Ein germanistisches Jubiläum. In: Germanistica Pragensia 18/1, 2005, S. 7-10.

MASAǨÍK, Zdeněk - BROM, Vlastimil: Historische Entwicklung des Deutschen: Übersichtstabellen Kommentare - Textproben. Brno: Masarykova univerzita v Brně 2005. (129 S.) [Lehrbuch]

Lenka Vaňková - Gundolf Keil: Mesuë und sein „Grabadin“. Ein Standardwerk der mittelalterlichen Pharmazie. Edition - Übersetzung - Kommentar. Ostrava 2005, 294 S. In: BBGN 20, 2005, S. 205-207. 
Lenka Vaňková: Medizinische Fachprosa aus Mähren, Wiesbaden 2004. 286 S. E゚ 226 S. Edition. In: BBGN 19, 2005, S. 223, 225-226.

Libuše Spáčilová - Vladimír Spácili: Památná kniha olomoucká z let 1430-1528 (Kodex Václava z Jihlavy), Olomouc 2004. 611 S. Ev Anlagen. In: BBGN 19, 2005, S. 223-225.

Zum 100. Geburtstag von Prof. Leopold Zatočil. In: BBGN 19, 2005, S. 9-10.

Die Erforschung des Frühneuhochdeutschen in Mähren aus methodologischer Sicht. In: PFAU, Christine - SLÁMOVÁ, Kristýna (hrsg.): Deutsche Literatur und Sprache im Donauraum. Olomouc: Univerzita Palackého v Olomouci 2006, S. 303-311.

Die linguistische Germanistik in Brünn - Antonín Beer und Leopold Zatočil. In: TVRDÍK, Milan VODRÁŽKOVÁ-POKORNÁ, Lenka (hrsg.): Die Germanistik in den Böhmischen Ländern im Kontext der europäischen Wissenschaftsgeschichte (1800 bis 1945). Wuppertal: Arco Wissenschaft 2006, S. 105-112.

MASAŘÍK, Zdeněk - HROZOVÁ, Marie: Nemotice: obec pod Nemotinkem v proměnách staletí (sbornik vydaný u príležitosti 680 let od proní pisemné zminky) [Nemotitz: Ein Dorf unter Nemotinek im Wandel der Jahrhunderte. Ein Sammelband anlässlich des 680. Gedenkjahres der ersten schriftlichen Erwähnung]. Nemotice: Obecní úřad Nemotice 2007. (83 S. + 12 S. Bildbeilage)

Bemerkungen zur These des Prager Linguistischen Zirkels über die Problematik der Sprachbünde. In: KRATOCHVÍlOVÁ, Iva - NÁLEPOVÁ, Jana: „Sprache: Deutsch.“ Beiträge des internationalen germanistischen Symposiums Opava/Sambachshof 5.-11. 10. 2007. Opava: Slezská univerzita, Filozoficko-př́rodovědecká fakulta, Ústav cizích jazyků 2008, S. 69-75.

Chronicon Henrici de Mügeln Germanice conscriptum - Německy sepsaná kronika Jindřicha z Mügeln. In: BARTOŇKOVÁ, Dagmar (et al.) (hrsg.): Magnae Moraviae fontes historici - Prameny k dějinám Velké Moravy I. Annales et chronicae. (2. Aufl.) Brno: Ústav klasických studií, Masarykova univerzita, Filozofická fakulta 2008, S. 317-321. [Teiledition und Übersetzung ins Tschechische]

Zu einigen Triebkräften der Sprachmischung in den frühneuhochdeutschen Mundarten Mährens. In: Acta facultatis philosophicae Universitatis Ostraviensis. Studia germanistica 3, Ostrava: Ostravská univerzita v Ostravě, FF 2008, S. 11-23.

Zur dialektalen Gliederung der Kanzleisprache Mährens. In: MOSHÖVEL, Andrea - SPÁČILOVÁ, Libuše (ed.): Kanzleisprache - ein mehrdimensionales Phänomen. Tagungsband für Prof. PhDr. Zdeněk Masařík, DrSc., zum 80. Geburtstag. Wien: Praesens Verlag 2009, S. 23-34.

Otfrids von Weissenburg Evangelienbuch - Evangelijni harmonie Otfrida z Weissenburgu. In: BARTOŇKOVÁ, Dagmar - VEČERKA, Radoslav (hrsg.): Magnae Moraviae fontes historici - Prameny k dějinám Velké Moravy II. Textus biographici, hagiographici, liturgici. (2. Aufl.) Praha: KLP - Koniasch Latin Press 2010, S. 290. [Teiledition und Übersetzung ins Tschechische]

\section{Quellen und Literatur zur Bio- und Bibliographie von Zdeněk Masařík}

BROM, Vlastimil: Prof. Zdeněk Masařik achtzigjährig. In: Germanoslavica. Zeitschrift für germanoslawische Studien 19/2, 2008, S. 120-122.

Digitálni knihovna Filozofické fakulty Masarykovy univerzity [Digitale Bibliothek der Philosophischen Fakultät der Masaryk-Universität]. https://digilib.phil.muni.cz/ [10. 11. 2016].

GREULE, Albrecht: Laudatio anlässlich der Feier des 80. Geburtstags von Prof. PhDr. Zdeněk Masařık, DrSc., in der Fronleichnamskapelle im Konvikt Olomouc/Olmütz, 28. März 2008. In: MOSHÖVEL, Andrea - SPÁČILOVÁ, Libuše (ed.): Kanzleisprache - ein mehrdimensionales Phänomen. Tagungsband für Prof. PhDr. Zdeněk Masařík, DrSc., zum 80. Geburtstag. Wien: Praesens Verlag 2009, S. 13-21, 
HUDEČEK, Roman: Komplexe Zusammenfassung der Beiträge zur Germanistik in SPFFBU, Reihe A in den Jahren 1952-1978 (Bc.-Dipl.). http://is.muni.cz/th/217647/ff_b/ (7. 11. 2016)

MALÁ, Jiřina: Prof. PhDr. Zdeněk Masařik, DrSc., zum 70. Geburtstag. In: BBGN 12, S. 11-13; Bibliographie von Zdeněk Masařik seit 1989, S. 13-14.

Publikationen von Zdeněk Masařik - Informationssystem der Masaryk-Universität. http://is.muni.cz/ publikace/publikace_prohlidka.pl?uco=2667 (7. 11. 2016).

STANOVSKÁ, Sylvie: Herrn Prof. PhDr. Zdeněk Masařık, DrSc., zu seinem Lebensjubiläum. In: BBGN 17, 2003, S. 11-13.

ŠKRDLÍKOVÁ, Jana: Antonín Beer, profesor germánské jazykovědy a redaktor časopisu Naše věda (Dipl.). Brno 2011. http://is.muni.cz/th/218034/ff_m/ (7. 11. 2016)

ZEMAN, Jaromír: Prof. PhDr. Zdeněk Masařrk, DrSc., zum 60. Geburtstag. In: BBGN 6, 1988, S. 7-9; Bibliographie von Zdeněk Masař́k, S. 10-13.

ZEMAN, Jaromír: Prof. PhDr. Zdeněk Masařık, DrSc., zum 80. Geburtstag. In: BBGN 22, 2008; S. 9-10.

Ein großer Dank gehört den Mitarbeiterinnen der Personalabteilung der FF MU, durch deren Entgegenkommen manche Angaben zum akademischen Werdegang Prof. Masaříks geklärt werden konnten.

Vlastimil Brom

im Namen der Mitarbeiterinnen und Mitarbeiter des Institut für Germanistik, Nordistik und Nederlandistik, FF MU 